\title{
Preparation and Properties of Segmented Quasi-Dynamic Display Device
}

\author{
Dengwu Wang ${ }^{1}$ and Fang Wang ${ }^{2}$ \\ ${ }^{1}$ Basic Department, Xijing University, Shaanxi, Xi'an 710123, China \\ ${ }^{2}$ Department of Chemistry and Chemical Engineering, Shaanxi Xueqian Normal University, Shaanxi, Xi'an 710061, China
}

Correspondence should be addressed to Dengwu Wang, farmouse403@mail.nwpu.edu.cn

Received 7 September 2012; Accepted 29 September 2012

Academic Editor: Fuli Zhang

Copyright (C) 2012 D. Wang and F. Wang. This is an open access article distributed under the Creative Commons Attribution License, which permits unrestricted use, distribution, and reproduction in any medium, provided the original work is properly cited.

\begin{abstract}
A kind of material, microencapsulated electronic ink, was prepared and supported on ITO glass used as backplane electrode and etched panels of the words "N-P-U" as pixel electrode. In addition, a quasi-dynamic display device was designed for electronic paper. The control signal generated by monostable process of 555 counter was used to drive the relay to work. The actual output of this kind of display was also observed. Through the combination of 555 counter and relay, quasi-dynamic electronic ink display was able to be achieved at the voltage of $15 \mathrm{~V}$. Furthermore, the delay time can be controlled within 0-10 seconds by adjusting monostable trigger time of the counter.
\end{abstract}

\section{Introduction}

The electrophoretic ink, a novel display material which can be called encapsulated electrophoretic display, is fabricated from a two-dimensional arrangement of microcapsule containing electrophoretic composition of a dielectric fluid and particles that visually contrast with the dielectric liquid and also exhibit surface charges. As this kind of display has attributes of good brightness and contrast, wide viewing angles, state bistability, and low power consumption when compared with liquid crystal displays, it has been subjected to intense research and development for a number of years $[1,2]$.

In previous research, we had prepared several kinds of microcapsules of red, green, blue, and white encapsulated electrophoretic inks, in which the pigmental particles encapsulated in microcapsules possessed reversible response behavior under a direct current electric field. However, in these papers, the prototype electronic ink display device, on which the electronic ink microcapsules were supported, can only achieve a static text [3-9].

Therefore, the purpose of this paper was to discuss the design of quasi-dynamic display device for electronic paper. Material used in this paper was prepared according to [10].
The ITO conductive glass coated with microencapsulated ink was used as backplane electrode, and etched panels of the words "N-P-U" as pixel electrode. The control signal generated by monostable process of 555 counter was used to drive the relay to work. Through the combination of 555 counter and relay, quasi-dynamic electronic ink display was able to be achieved. Furthermore, the delay time can be controlled within $0-10$ seconds by adjusting monostable trigger time of the counter.

\section{Display Film}

Electronic ink display is a kind of reflective paper-like display. Obviously, if the preparation of the film have a regular, smooth surface, it contributes to improve the display performance of the device. Figure 1 shows a schematic diagram of the reflective properties and corresponding SEM images. As can be seen, the irregular surface is able to increase the diffuse reflectance of the display device, which results to the decrease in luminance, contrast, and color saturation. If the film surface is smooth, the film may be formed quasi-mirror, and thus to improve the reflective properties of the device. Moreover, it is favorable to enhance the effective contact area between the backplane electrode and pixel electrode, thereby 


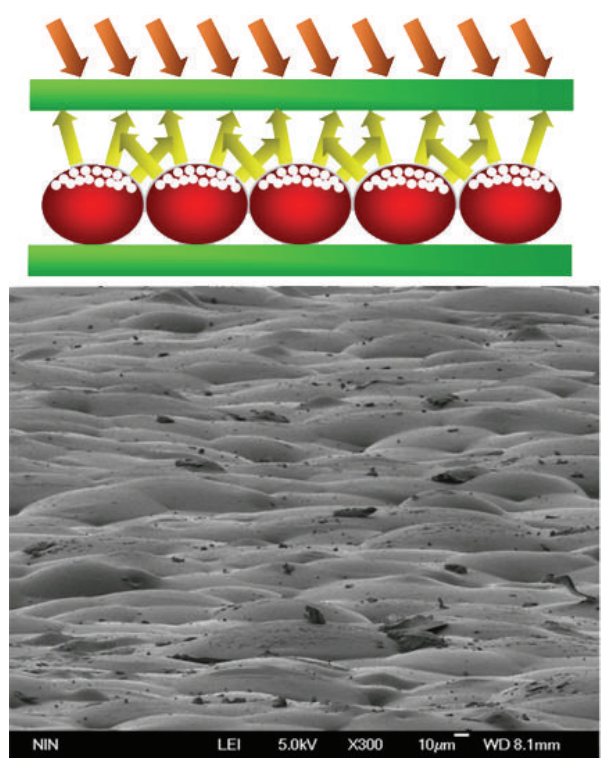

(a)
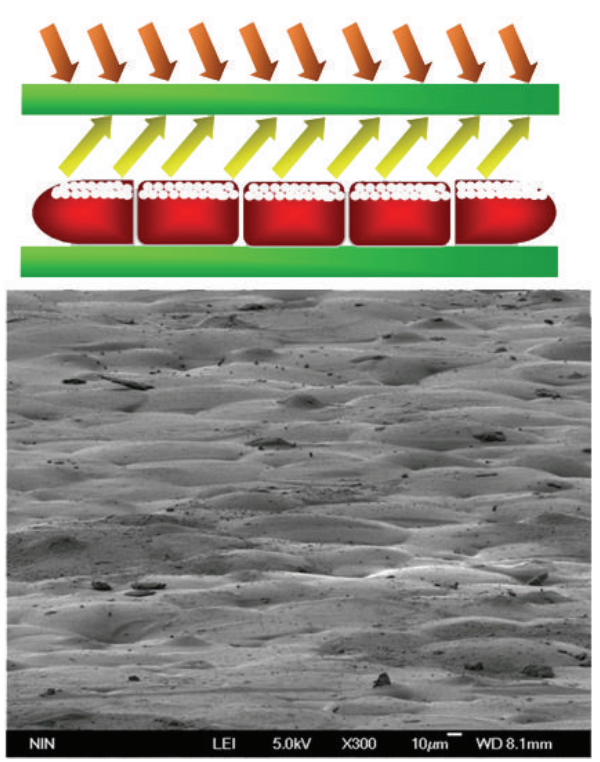

(b)

FIGURE 1: Schematic illustration with different surface morphology and corresponding SEM images of material display film.

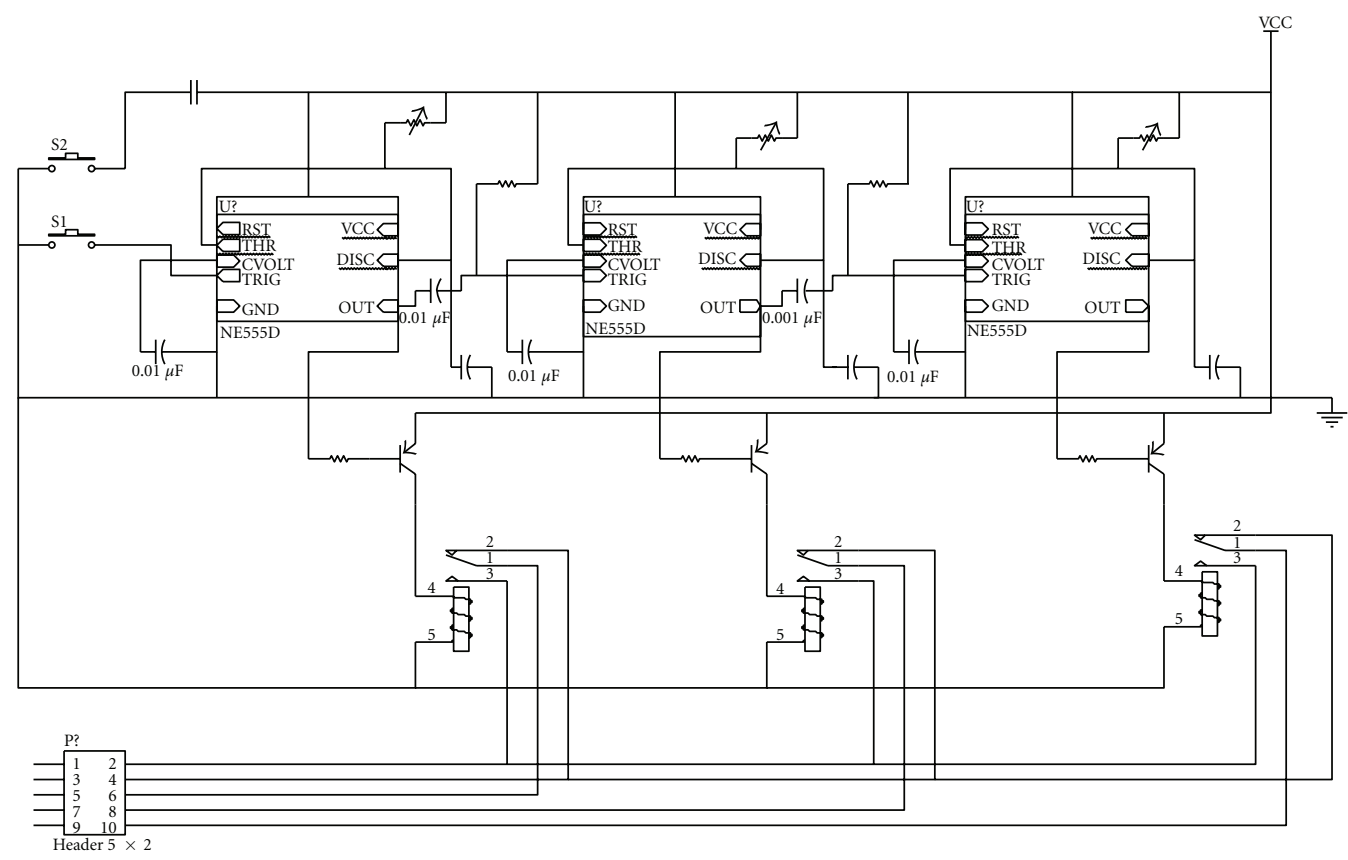

FIGURE 2: Control circuit diagram of sequential segmenting display.

reduce the driving voltage of the device, and improve the response speed of the display.

\section{Circuit Design}

The circuit diagram is shown in Figure 2. Herein, three 555 counters are connected in parallel and, respectively, worked in monostability. The run and reset control is achieved through the switches S1 and S2. Wherein, high voltage time of each monostable 555 counter is determined by the product of the value of the resistors and capacitors of respective connected 6 and 7 port. The high time can be expressed by

$$
T=1.1 R \times C .
$$

In the experiment, the set high time of the three counters $3 \mathrm{~S}, 6 \mathrm{~S}$, and $9 \mathrm{~S}$, respectively. By these means, three ports 


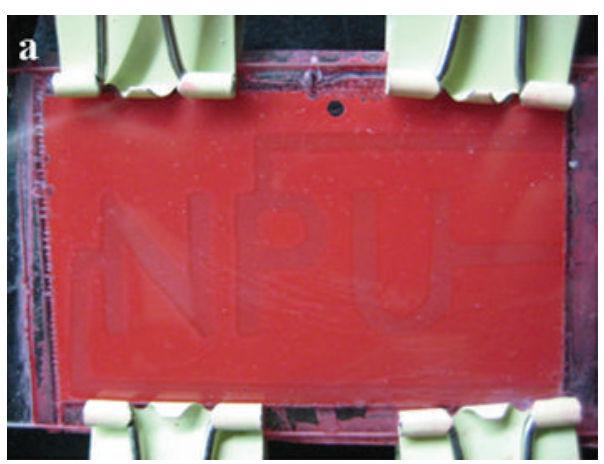

(a)

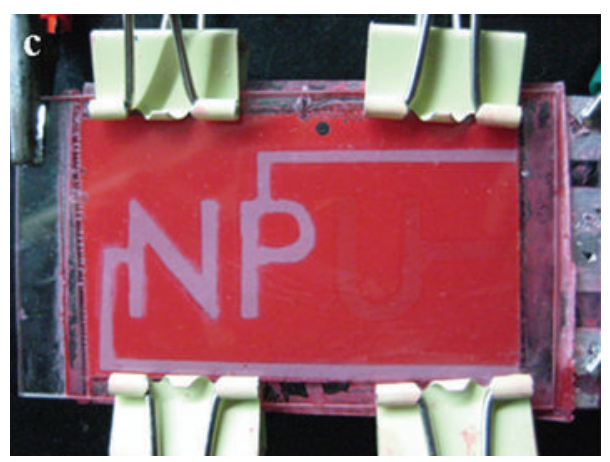

(c)

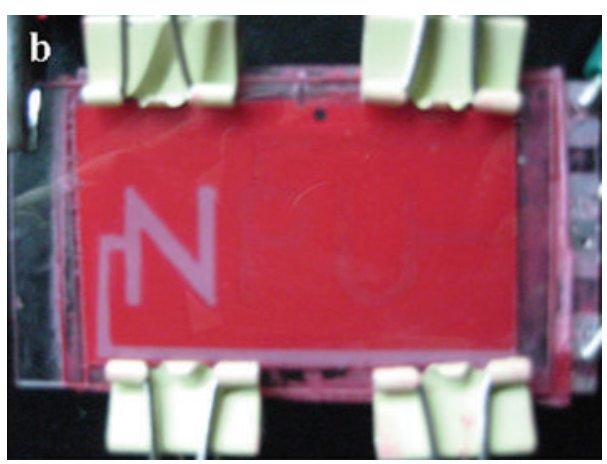

(b)

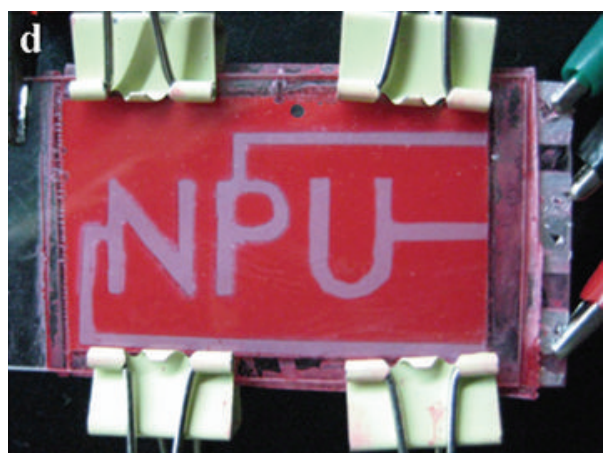

(d)

Figure 3: Picture of quasi-dynamic electrophoretic display.

of 1,2 , and 3 can be achieved on/off every $3 \mathrm{~s}$ to achieve subquasi-dynamic sequence.

\section{Results and Discussions}

The actual output of quasi-dynamic electrophoretic display is shown in Figure 3. Before test, a reverse electric field is applied, which makes the electrophoretic particles move to the backplane electrode, therefore, the pattern shows a shaded display. In our experiment, the electrophoretic display is able to be realized at $5 \mathrm{~V}$, but the display time will be prolonged. Therefore, the applied test voltage is $15 \mathrm{~V}$, which can ensure the device response to electric field quickly. As can be seen from Figure 3, when an electric field is applied to the device, the particles move to the pixel electrode and begin to sequentially display "N-P-U" image. It indicates that the prepared device has a quasi-dynamic driving character.

\section{Conclusions}

Improvements are needed in the design of device to meet the needs of dynamic video response. The combination of high performance display materials and device characterization research will be a primary focus in further work. In the end, a quasi-dynamic electrophoretic display driving device for electronic paper was demonstrated by employing the monostable working model. Furthermore, the delay time can be controlled within $0-10$ seconds by adjusting monostable trigger time of the counter.

\section{Acknowledgments}

This work was supported by the Research Projects of Department of Education of Shaanxi Provincial (Grant no. 12JK1074, 11JK0827) and Key Projects of Shaanxi Xueqian Normal University (Grant no. 2012KJ009).

\section{References}

[1] H. Yan, Z. Chen, Y. Zheng et al., "A high-mobility electrontransporting polymer for printed transistors," Nature, vol. 457, no. 7230, pp. 679-686, 2009.

[2] X. P. Zhao and H. L. Guo, "Preparation and properties of micro- and nano-microcapsules for electronic ink," in New Research on Optical Materialspp, p. 53, Nova Science, 2007.

[3] H. L. Guo, X. P. Zhao, and J. P. Wang, "The relation between narrow-dispersed microcapsules and surfactants," Journal of Microencapsulation, vol. 22, no. 8, pp. 853-862, 2005.

[4] H. L. Guo and X. P. Zhao, "Preparation of a kind of red encapsulated electrophoretic ink," Optical Materials, vol. 26, no. 3, pp. 297-300, 2004.

[5] J. P. Wang, X. P. Zhao, and D. W. Wang, "Preparation of nanocapsules containing the two-phase core materials," Journal of Microencapsulation, vol. 24, no. 8, pp. 757-766, 2007.

[6] J. P. Wang, X. P. Zhao, H. L. Guo, and Q. Zheng, "Preparation and response behavior of blue electronic ink microcapsules," Optical Materials, vol. 30, no. 8, pp. 1268-1272, 2008.

[7] F. L. Zhou, D. W. Wang, Q. Miao, and X. P. Zhao, "Preparation and properties of flexible electronic ink display device," Material Review, vol. 22, no. 6, pp. 149-151, 2008. 
[8] H. Guo, X. Zhao, and J. Wang, "Synthesis of functional microcapsules containing suspensions responsive to electric fields," Journal of Colloid and Interface Science, vol. 284, no. 2, pp. 646651, 2005.

[9] Y. Wang, H. Guo, J. Wang, and X. Zhao, "The preparation of electrophoretic ink microcapsules by using urea formaldehyde oligomer," Acta Polymerica Sinica, no. 2, pp. 268-272, 2004.

[10] D. W. Wang and X. P. Zhao, "Microencapsulated electric ink using gelatin/gum arabic," Journal of Microencapsulation, vol. 26, no. 1, pp. 37-45, 2009. 

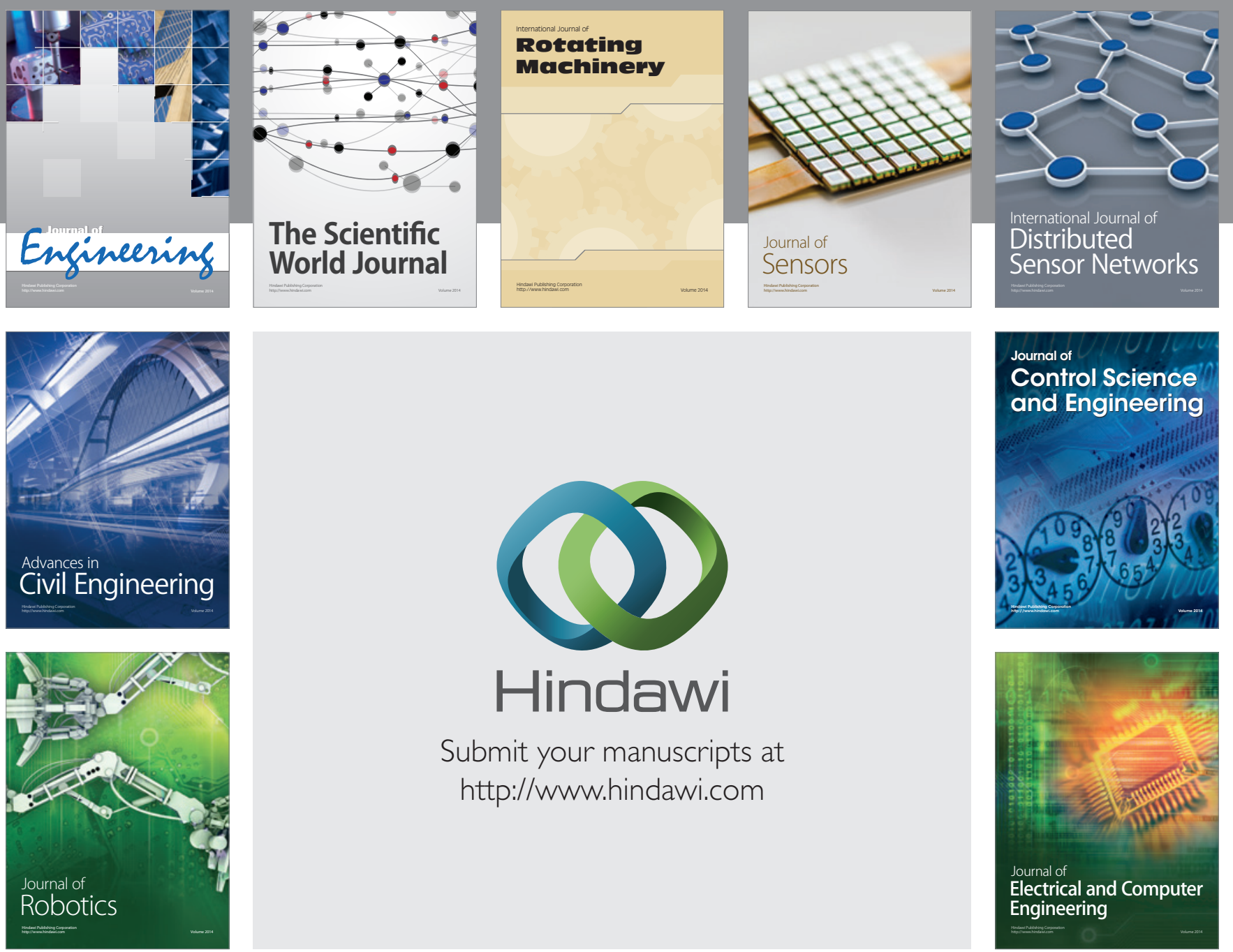

Submit your manuscripts at

http://www.hindawi.com
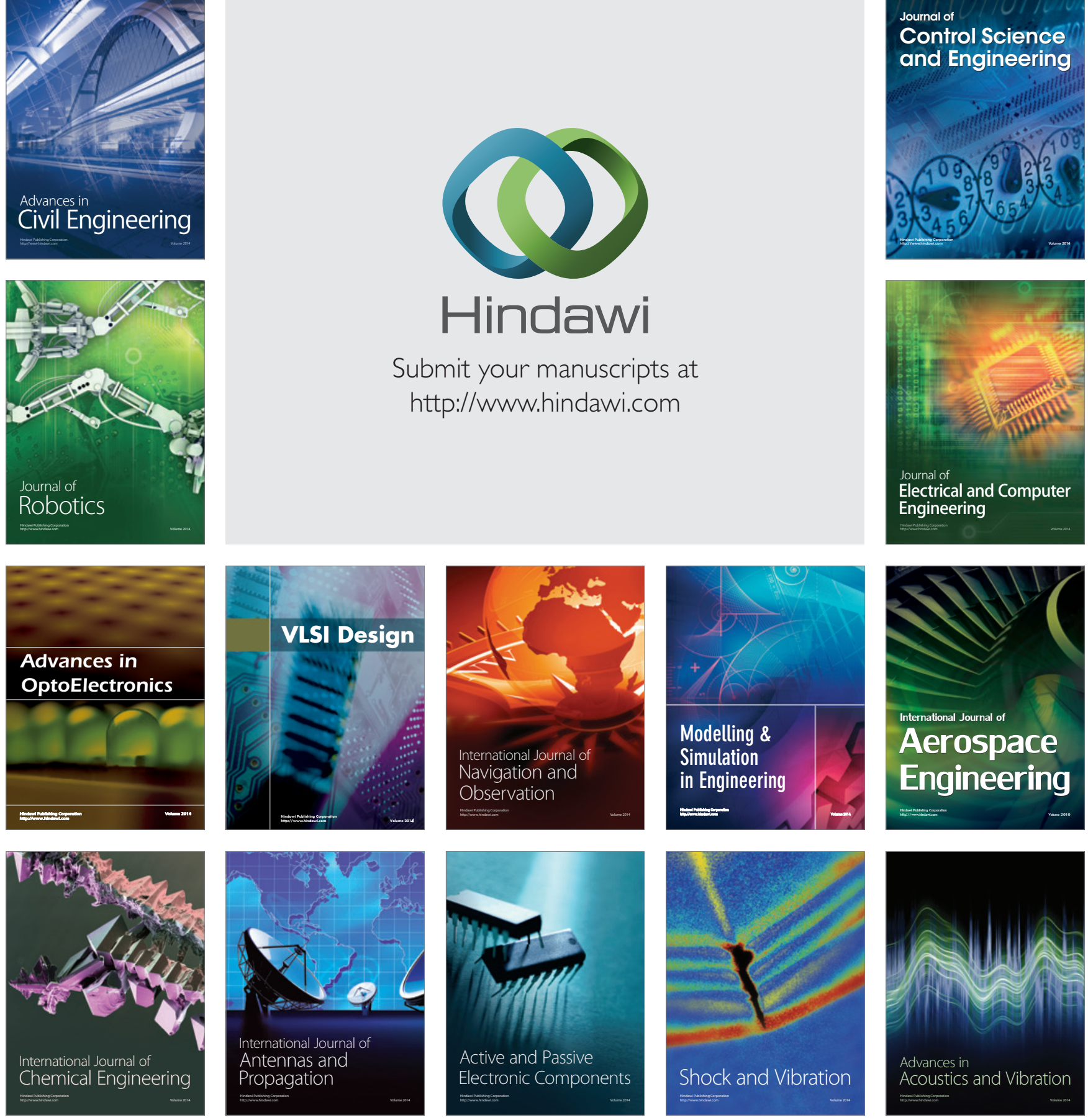